\title{
Porous Carbon doped by different nitrogen sources and its Electrochemical Properties
}

\author{
Mengqi Du ${ }^{1}$, Yanshuang Meng ${ }^{1}$, Lei Wang ${ }^{1}$, Chaoyu Duan ${ }^{1}$, \\ Fuliang $\mathrm{Zhu}^{1,3, *}$ and Yue Zhang, \\ ${ }^{1}$ School of Materials Science and Engineering, Lanzhou University of Technology, Lanzhou \\ 730050,China \\ ${ }^{2}$ Department of Mechanical and Industrial Engineering, Texas A\&M University-Kingsville, \\ Kingsville, Texas, 78363, USA \\ ${ }^{3}$ State Key Laboratory of Advanced Processing and Recycling of Non-ferrous Metals, Lanzhou \\ 730050, China \\ *E-mail: chzfl@126.com (Fuliang Zhu), yue.zhang@tamuk.edu (Yue Zhang)
}

doi: $10.20964 / 2018.05 .51$

Received: 11 January 2018 / Accepted: 5 March 2018 / Published: 10 April 2018

Nitrogen doped porous carbons (NPCs) were synthesized by using a self-sacrificing template method. The obtained NPCs exhibit large amount of mesopores and high pyrrolic $\mathrm{N}$ and pyridine $\mathrm{N}$ content. Because the pyrrolic $\mathrm{N}$ and pyridine $\mathrm{N}$ facilitate the formation of defects and vacancies, the electrochemical properties of NPCs are significantly improved. The NPCs delivers a high reversible capacity of $621 \mathrm{mAh} \mathrm{g}^{-1}$ at $0.1 \mathrm{C}$ after 50 cycles and excellent rate capacity of $456 \mathrm{mAh} \mathrm{g}^{-1}$ at $1 \mathrm{C}$, showing great potentials as anode materials for Li-ion batteries (LIBs).

Keywords: N-doped porous carbon; Lithium battery; Anode material; Self-sacrifice template

\section{$\underline{\text { FULL TEXT }}$}

(C) 2018 The Authors. Published by ESG (www.electrochemsci.org). This article is an open access article distributed under the terms and conditions of the Creative Commons Attribution license (http://creativecommons.org/licenses/by/4.0/). 